\title{
Contradiction of Economic Growth vs Population Growth in Asia: A Sociological Appraisal
}

Mohammad Taghi Sheykhi

Professor Emeritus of Sociology, Alzahra University,Tehran, Iran.

*Corresponding Author: Mohammad Taghi Sheykhi, Professor Emeritus of Sociology, Alzahra University, Tehran, Iran.

Received date: February 16, 2021; Accepted date: March 05, 2021; Published date: March 10,2021

Citation: Mohammad T Sheykhi. (2021) Contradiction of Economic Growth vs Population Growth in Asia:A Sociological Appraisal. Journal of Clinical and Laboratory Research. 2(2) DOI: 10.31579/ 2768-0487/010

Copyright: @2021 Mohammad Taghi Sheykhi. This is an open-access article distributed under the terms of the Creative Commons Attribution License, which permits unrestricted use, distribution, and reproduction in any medium, provided the original author and source are credited.

\begin{abstract}
The present article sociologically appraises how the two variables of economic growth and population growth are related. The two variables had a different relationship with each other before industrialization started as compared with the modern era. In older times, when societies were agricultural, there seemed to be no contradiction between the two. At that time, as many as children were born, used to get engaged in agricultural sector. Moreover, at that time, death rate was also high. But, later and due to the emergence of industrialization, technologies and mechanization, gradually contradiction of economic growth versus population growth appeared. This is where socio-clinical study of economic growth and population growth finds its necessity. Sociologically speaking, Asian countries need to pay more attention to the two variables, and thereby minimize the emerging contradiction. While average life expectancy is currently over 73 years in Asia (WPDS, 2020), Asian countries must predict feeding, nursing, housing and medications of such aging people for the years to come. It must be notified that population aging as a new trend is the outcome of economic growth. Immune systems of all increasing aging people must be on the agenda in a socio-clinical framework.
\end{abstract}

Keywords: paradoxical phenomenon; economic growth; population growth; immune systems; contradiction

\section{Environment and development}

Healthy and productive life is possible in harmony with nature. This means that a kind of balance must be struck between financial output and natural resources. Environmental management, environmental studies, environmental engineering, and so on, themselves provide environmental health benefits; That is, what can itself guarantee development in its various dimensions. Excessive exploitation of natural resources leads to erosion and consequent degradation of the environment. Therefore, proper utilization of its natural resources and environment can create more guarantees for future generations. Today, many less developed countries, which are facing increasing population and manpower, are inevitably endangered natural resources and the environment in those communities. This in itself creates potential dangers for future generations in those societies.

Environmental protection itself is influenced by environmental legislation, environmental ethics and education. From a sociological point of view, the necessary laws related to the environment should always be enacted and implemented as needed. Likewise, creating appropriate ethics, necessary norms, and guidelines of this kind can, as much as possible, while maintaining the health of the environment, also lead to development in its various dimensions. Therefore, the environment must never be sacrificed in order to achieve development. Environmental advocacy; That is, the ideology or social movement related to the environment itself advocates various aspects of environmental health. Orientation to the environment seeks to establish a harmonious relationship between humans and natural systems. This trend has gained a lot of fans around the world today; That is, a movement that leads to better health, longer life expectancy, healthier economic movement, and so on. In general, environmentalists favor sustainable resource management; That is, a process that itself requires proper policy-making, environmental protection, ecology, human rights and the like. Environmental protection and its advocacy ideology began in the 1980s. Likewise, global warming and population growth are themselves significant as motivations for this movement. While this movement originally originated in industrial societies, its introduction and spread within developing countries is also of considerable importance, and ultimately brings environmental health to such societies.

\section{Different dimensions of the environment}

Various issues affect the quantity and quality of the environment, the most important of which are:

Energy, which itself plays a central role in creating any challenge or opportunity in today's world, and to which the contemporary world is largely dependent. Due to economic-industrial development and the expansion of communications, widespread urbanization, and the like, the human race needs more energy than ever before. Therefore, the rational 
use of energy so that future generations can have a share in it, is itself emphasized by development economists and environmental sociologists. Job opportunities, security, climate change, rising incomes, etc., are all related to energy; That is, energies including solar energy, renewable energy, improving energy efficiency, new energies and the like.

Cities are known as the center of ideas, trade, culture, science, productivity, social development and the like, and this has led to more social and economic development of individuals. At the same time, the general challenges of these cities, including congestion, congestion, lack of resources to provide services, lack of housing, poor infrastructure and the like, can be seen within cities today. During the twentieth century, urban areas have expanded more than ever before. Industrial and economic development have played a role as major factors in attracting population to these areas. Although this movement has more or less stopped in industrialized countries today; That is, there is no more urbanization, but the cities of less developed countries are expanding widely. In the absence of monitoring of such cities, the environment is exposed to various hazards in various forms. Therefore, systems related to the environmental organization, municipalities and other relevant agencies should increasingly exercise their control over evolving urban areas. Likewise, successful cities are those that reduce pollution and poverty by improving their resources; That is, they deduct the cost of conserving resources and environmental health from their findings.

Food supply also depends on proper agriculture, exploitation of fishery resources, proper exploitation of forests and the like. Today, following the increase in the consumer population, food supply is also of considerable importance. Therefore, the construction and creation of infrastructure facilities related to food supply; Such as agriculture, various techniques of exploitation of agricultural resources, exploitation of marine food resources, as well as forest conservation, are themselves of considerable importance. Otherwise, restrictions on food supply, increasing poverty, and endangering the environment await such communities. Today, many less developed countries, which are also rapidly urbanizing, face such challenges.

Environmental and developmental resources must work to meet the 925 million hungry people in the world in 2012 and the more than 2 billion hungry people worldwide in 2050. Socio-economic development plans should always make the necessary investments in agriculture and food production due to the increase in population in the coming years; So that by 2050 , the poverty, malnutrition and food shortages index can be gradually reduced. These problems are generally present in developing countries. The Rio Conference (2012) has also placed great emphasis on this policy. Therefore, food and agriculture themselves play a key role in development and are considered as the eliminators of hunger and poverty. Developing societies, which generally should be more active in their agricultural sector, unfortunately in many cases do not have an increase in production (surplus production), and in return have to be either in short supply, or if possible a portion of the food they need From other countries. At the same time, industrial societies, given that the main axis of their economy is focused on industry and industrial production, at the same time show the maximum utilization of their agricultural capacities; In such a way that they export their surplus production to other less developed societies and ...

Clean and accessible water for all is an undeniable necessity in the world in which we live. While there is not enough water in the world today, millions of people, especially children, die each year from diseases caused by lack of water resources, unhealthy water, lack of sanitation, and so on, due to the weak economy and poor infrastructure. They shake hands. However, in the conditions of better water resources management, water sanitation, even in cases of drought, the shortage of water resources can be largely compensated. Therefore, in the present age of water engineering, measured systems of water resources and the like, to a large extent can provide security related to water resources.

Natural disasters such as earthquakes, floods, droughts, tsunamis and the like have devastating effects on people, the environment and the economy. In such circumstances, effective plans and programs lead to improvement and healing. While weak plans and options lead to greater vulnerability, ultimately, with the world's population now more than 7.3 billion, adopting effective environmental policies should be a priority for countries.

\section{References}

1. David, H. (2010), Implications of Population Aging for Economic Growth, Oxford University Press.

2. Haq, M. H. and Haq, K. (1998), Human Development in South Asia, Karachi, Oxford University Press.

3. Heady, D. D. (2009), The Effects of Population Growth on Economic Growth: A Meta-regression Analysis of the Macroeconomic Literature, Population and Development Review, 35, 221-248.

4. Wesley, E. (2017), The Role of Population in Economic Growth, Sage Open Access.

5. World Population Data Sheet, (2020), Population Reference Bureau, Washington DC 